\title{
Performance analysis of voltage regulation in diesel-wind generation
}

\author{
Shashikant $^{1 *}$, S.K. Srivastava ${ }^{2}$ \\ ${ }^{I^{*}}$ Department of Electrical Engineering, Northern India Engineering College Lucknow, INDIA \\ ${ }^{2}$ Department of Electrical Engineering, Madan Mohan Malviya Engineering College Gorakhpur, INDIA \\ "Corresponding Author: e-mail: shashi_kant52@rediffmail.com, Mob. +91-9415713130
}

\begin{abstract}
In presented paper performance analysis of the hybrid diesel-wind energy conversion system has presented. Electrical energy is generated by the two sources one source is the diesel engine generator and the other source is the wind energy conversion system the supply is provided to the isolated load. The voltage is regulated at the load side . The electrical energy produced by the wind turbine at constant speed is connected to the specific load by the rectifier, d.c link and pulse width modulation inverter. In this work the value are assumed in the IS system. Voltage regulation is done with the use of PI controller and simulation results are performed on the MATLAB (new version).
\end{abstract}

Keywords: Wind energy, diesel generator, induction generator, rectifier, inverter, voltage regulator.

\section{Introduction}

Energy is the base of the economy of each country in the world. There are many aspects for the energy in the world. As the living standard is raised the energy consumption is raised. As the population and the living standard is increased the energy crisis started. Our main concern is the wind energy, it can be used economically for the generation of electrical energy, provide mechanical power can be used in the water pumping. There are two major causes for the wind first is the heating and cooling of the atmosphere in the world due to this convection currents and the second is the rotation of earth both self rotation and the rotation around the sun.In country named as Denmark where the windmill was installed in the 1259, Installation of the windmill was in a village. Without using the fossil fuel the produced energy starts contribution to fulfill the requirement of energy in Denmark. In the start the use of produced energy was used for water pumping and grinding grain thereafter in the 1616 the number of windmills were installed for the providing energy for the threshing machine and grinding mills.(Andersen, 2007).

In the world installed wind power capacity is increasing $30 \%$ per year. Green house gas emission in the whole world for the production of the electrical energy 2000 fuel mix is $0.572 \mathrm{~kg}$ of equivalent $\mathrm{Co}_{2}$ per $\mathrm{kWh}$. Total electricity generation was 14617 TWh in the 2000 so for the emission of the $\mathrm{Co}_{2}$ was 8364 megatons. Developments in the wind energy technologies reduce the emission of the green houses gases (Wang and Chang, 2004 ).

So far we proposed the model for the generation of the electricity by the use of the wind energy and the diesel energy. In the proposed system we included the wind turbine which worked as the fixed speed wind turbine, wind energy was converted in to the mechanical energy by the turbine and the generated mechanical energy is converted into the electrical energy by the use of the induction generator the power generated by the wind generation is $15 \mathrm{KW}$ at the voltage of the $600 \mathrm{~V}$.Electrical energy is also generated with the diesel energy so for we used the diesel engine with the synchronous generator the electrical energy generated by the diesel generation is $35 \mathrm{KW}$ and the voltage is also $600 \mathrm{~V}$.Now the total generated electrical energy is supplied to the isolated load of $50 \mathrm{KW}$, the load is resistive, by the use of the power electronics circuit.

Power generated by the both sources is a.c now it is converted into the d.c by the use of the rectifier unit this rectifier unit is uncontrolled, rectified supply is now goes to the inverter unit by the d.c link this d.c link contains the inductor and the capacitor. Inverter unit consists of IGBT the controlling of the inverter is by the voltage regulator and the pwm generator. Output of the inverter is now filtered by the use of the L-C filter, filtered supply is now provided to the isolated load. We regulate the supply by the voltage regulator which provides the electrical signals to the pwm generator this generator generates the signals which are 
applied to the gate of the IGBT used in the inverter unit.In the proposed model we regulated voltage $270 \mathrm{~V}$ nominal phase to phase voltage. Now a days the new researches are in the field of the power electronics devices due to the use of power electronics we can easily controlled our system than the conventional methods in the conventional methods there are more losses in comparison with the power electronics control. In proposed model we have used the wind generation, wind energy is absolutely free in the atmosphere by the use of wind energy we can generate electrical energy which can fulfill our required electrical energy in cheap manner.

\section{Wind Turbine Generation}

Wind energy for the electrical energy generation has low impact on the environment the interest of the whole world there in the recent years. We can extract hundreds of kilowatt power by the advancement in the wind turbine. When wind energy conversion system is connected with grid they produce supplement base power generated by the nuclear, thermal and hydro power plants. (Datta and Ranganathan, 2003).

In the energy conversion by the wind energy has the different components such as wind turbine which converts the energy in the wind stream in the spin of the turbine the spin is the mechanical energy, now this mechanical energy is converted into the electrical energy by the different types of the generator such as synchronous generator, induction generator and the use of the permanent magnet synchronous generator is also their according to the electrical power generation these different types of the generators are used.

The electrical power generated is of three types

- $\quad$ Small power generation

- $\quad$ Medium power generation

- $\quad$ Large power generation

Wind contains energy due to the quality of the motion the system having the capability of extraction of this energy so for this energy can be used in the different form may be in the form of mechanical energy or in the form of the electrical energy. There are some factors which are responsible for the output of the wind energy first is the speed of the wind blowing in the atmosphere second is the area in which the wind is striking and the third is the conversion efficiency of the whole system. (Teri ENVIS, 2005/2006)

The energy and the power can be related to each other, energy per unit time is said that power so for we can make the relation in the such as

$$
\begin{aligned}
& \qquad P_{\text {wind }}=\frac{E_{\text {wind }}}{t} \\
& \mathrm{P}_{\text {wind }}=\text { wind power } \\
& \mathrm{E}_{\text {wind }}=\text { kinetic energy of the wind } \\
& \mathrm{t}=\text { time }
\end{aligned}
$$

Kinetic energy of the wind can be represent in the mathematical formulation assuming that the air is striking on the blade of the wind turbine and the area swept represented by the $A_{\text {blade }}$ the mass of the air transversing this area is $m_{\text {wind }}$ the density of the air is represented by the $\rho_{\text {air }}$ and the velocity of the wind is $V_{\text {wind }}$ (Jan Vergauwe et. al. 2006)

The mass of the wind will be represented by the

$$
M_{\text {wind }}=\rho_{\text {air }} \times A_{\text {blade }} \times V_{\text {wind }}
$$

The kinetic energy will be represented by the

$$
E_{\text {wind }}=0.5 M_{\text {wind }} \times V_{\text {wind }}^{2}
$$

Putting the value of $\mathrm{m}_{\text {wind }}$ in the equation (3)

$$
E_{\text {wind }}=0.5 \rho_{\text {air }} \times A_{\text {blade }} \times V_{\text {wind }} \times V_{\text {wind }}^{2}
$$

So for the equation can be represented by the,

$$
E_{\text {wind }}=0.5 \rho_{\text {air }} \times A_{\text {blade }} \times V_{\text {wind }}^{3}
$$

Then the power can be represented by the

$$
P_{\text {wind }}=0.5 \rho_{\text {air }} \times A_{\text {blade }} \times V_{\text {wind }}^{3}
$$

$\mathrm{P}_{\text {wind }}$ represent the wind power which is conversion of the wind blowing into the mechanical power the output power from the wind turbine will depend upon this power because the factor of efficiency so the mechanical power 


$$
P_{\text {wind }}=\left(0.5 \rho_{\text {air }} \times A_{\text {blade }} \times V_{\text {wind }}^{3}\right) \times C_{p}(\lambda, \beta)
$$

$\mathrm{C}_{\mathrm{p}}=$ coefficient of performance for turbine function

$\beta=$ pitch angle

Tip speed ratio can be defined as the ratio (Srighakollap and Sensarma, 2008)

$$
\lambda=\frac{.2 D \omega_{m}}{V_{\text {wind }}}
$$

Let the $\mathrm{D}$ is the diameter of horizontal axis aero turbine then we can represent the area

$$
A_{\text {blade }}=0.25 \pi D^{2}
$$

By the equation (7) we can say that the power is dependent on the density of the air in the different weather conditions density of the wind will be changed so for the power by the wind will be dependent on these conditions, area swept by air the area is depending upon the diameter of the horizontal axis so for as the diameter will increased the wind power will be more extracted and as the area will decreased the wind power extracted will be low, the cubical power of the wind velocity as the wind speed increases so the wind power extracted will be more if the wind speed decreases so the wind power extracted will be low and coefficient of performance for turbine function depend upon the two values one is pitch angle and other is the tip speed ratio. The coefficient of performance for turbine function $\left(\mathrm{C}_{\mathrm{p}}\right)$ is defined as the ratio of the actual turbine power to theoretical turbine power it can be represented by the (Tianxiang et al., 2010)

$$
\begin{aligned}
C_{p} & =\frac{P_{m}}{P_{\text {wind }}} \\
C_{p} & =\frac{P_{m}}{.5 \rho_{\text {air }} \times A_{\text {blade }} \times V_{\text {wind }}{ }^{3}}
\end{aligned}
$$

In the turbine the tip speed ratio can be controlled so for the power extracted by the wind turbine can be maximize

\section{Induction Generator Model}

In the working we use the dq representation the squirrel cage induction machine can be represented by the equations which is the called the mathematical modeling of the machine so for we can neglect the magnetic saturation so for we can write in the rotating frame (Mullane and O’Malley, 2005)

For the electrical system

$$
\begin{aligned}
& i_{d s} \times R_{s}=V_{d s}-\left(\frac{d \varphi_{d s}}{d t}\right)+\omega_{q s} \\
& i_{q s} \times R_{s}=V_{q s}-\left(\frac{d \varphi_{q s}}{d t}\right)-\omega_{d s} \\
& i_{d r} \times R_{s}=V_{d r}-\left(\frac{d \varphi_{d r}}{d t}\right)+\left(\omega-\omega_{r}\right) \varphi_{q s} \\
& i_{q r} \times R_{s}=V_{q r}-\left(\frac{d \varphi_{q r}}{d t}\right)+\left(\omega-\omega_{r}\right) \varphi_{d r}
\end{aligned}
$$

rotational speed of the machine and rotor electrical angular velocity are related to each other by the formulation

$$
2 \omega_{r}=P_{z} \omega_{m}
$$

For the mechanical system

$$
2 H\left(\frac{d \omega_{m}}{d t}\right)=T_{e}-F \omega_{m}-T_{m}
$$




$$
\omega_{m}=\frac{d \theta_{m}}{d t}
$$

Electromagnetic torque developed in the generator can be represented as

$$
T_{e}=1.5 P_{z}\left(\varphi_{d s} \times i_{q s}-\varphi_{q s} \times i_{d s}\right)
$$

Relation between the electromagnetic torque and the mechanical torque applied by the wind turbine can be expressed as

$$
\frac{\omega_{m}}{d t}=\frac{1}{J\left(T_{e}+T_{m}\right)}
$$

In the model when we working in the simulation the constatnt speed working is there so for the values of the value of the rotor component $\mathrm{V}_{\mathrm{dr}}$ and $\mathrm{V}_{\mathrm{qr}}$ becomes zero

\section{Modelling and Control of Diesel Engine with Synchronous Generator}

In the diesel engine generation the electrical power is generated by the use of mechanical power and the mechanical power is generated by the use of diesel engine in the diesel engine fuel is combusted which produce the mechanical power output speed of the diesel engine and the mechanical power output can be controlled by the governor system while the voltage is controlled by the use of excitation system (Drouilhet, 2001)

In the presented model block represent the diesel engine speed and voltage control the block consists of the diesel engine, diesel engine governor and the excitation system so for the diesel engine governor is used for the controlling of the diesel engine in the diesel engine the combustion of the diesel takes place. Governor system is used for the controlling of the diesel generator so for we get the desired mechanical power and the desired speed in the same manner the excitation system is also is there which is used for the controlling of the field excitation voltage mechanical power and the excitation voltage achieved by this block is applied to the synchronous generator.

In the diesel generator actuator dynamics can be represented by the first order system consisting the time constant $\tau_{2}$ with gain $\mathrm{K}_{2}$ and the variable gain $K_{1}$ is represented by the combustion system which depending upon the dead time, output power and the speed. So for the total gain depends upon engine rotational speed and the total mechanical power transmitted by the system we can formulate the total gain (Pena et al., 2008)

$$
K_{p t}=K_{1} \times K_{2}
$$

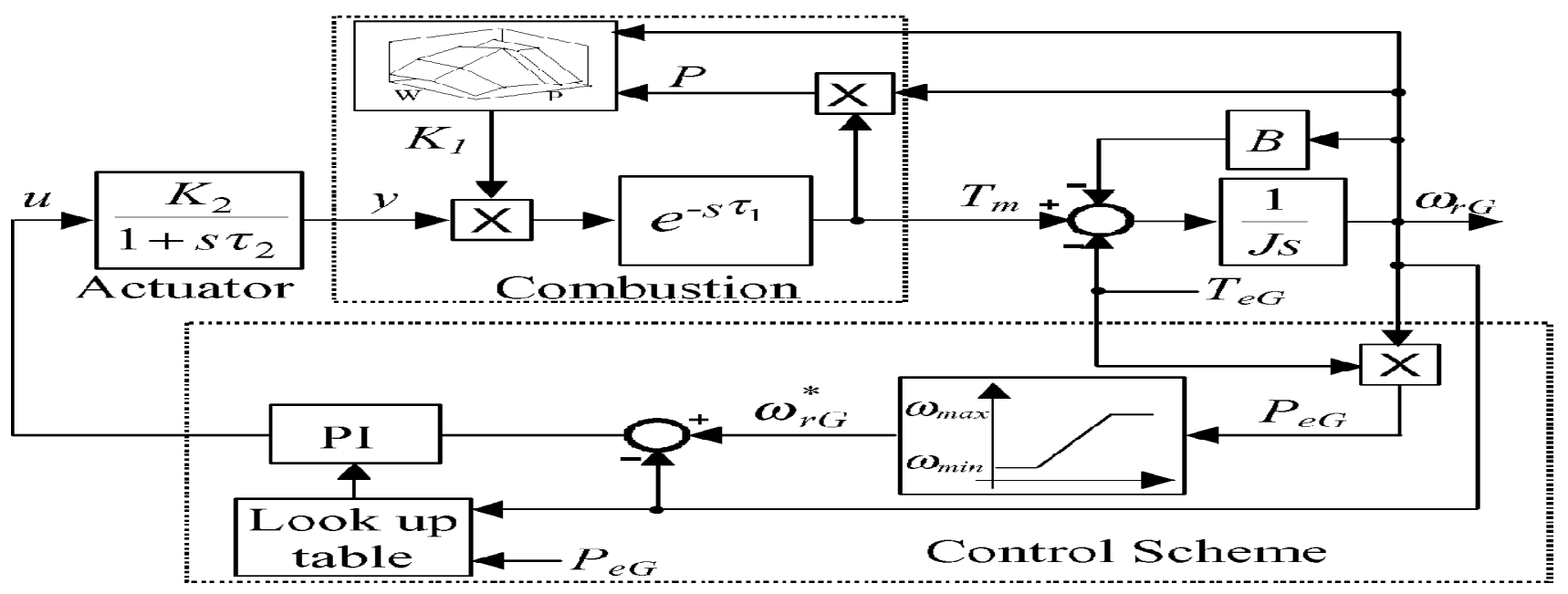

Figure 1. Diesel engine model

$$
\tau_{1}=\frac{60 s_{t}}{2 N n}+\frac{60}{4 N}
$$


Where $s_{t}$ is the strokes of the engine $\mathrm{N}$ is the speed of the engine and $\mathrm{n}$ is the no of cycles.

By the time domain technique synchronous generator model is obtained by the general flux model of the synchronous machine so for the we can present the mathematical representation of the synchronous generator (Pinto et al., 2006)

$$
\begin{aligned}
& {[V]=-[I] \times[R]-\frac{d[\psi]}{d t}} \\
& {[\psi]=[I] \times[L]}
\end{aligned}
$$

\section{Simulation Results and Discussion}

In the proposed system we are generating the electrical energy by the two processes in the first the conventional method which is the diesel generator while the second one is the wind energy conversion so for the electrical power is generated in the isolated system and supplying the electrical energy so the performance of the energy conversion is discussed in this chapter in the system we are regulating the voltage so for we are using the rectifier, inverter, d.c link and the filter so for the performance is achieved across the rectifier, inverter, d.c link and the output side.

Proposed model having the full load in this case the electrical energy is generated in the two systems first is the diesel generator and the other is the wind energy conversion system the combined electrical energy is transmitted to the load by the power electronics system in the system there are different parts where we are checking the performance first of all the generated supply is a.c which is converted in the d.c by the rectifier so the first we discuss the d.c voltage performance

\subsection{D.C voltage performance}

Proposed system is simulated for the .1 second the a.c voltage is converted into the d.c by the use of rectifier and the filter is used which consists of the inductor and the capacitor the output is the d.c which is fed to the inverter. In the initial state the input to the rectifier is zero at the $\mathrm{t}=0$ so the d.c is zero as the time goes on the d.c voltage rises instantaneously with in $\mathrm{t}=.01$ second and after some fluctuations it rises and after the sometime it rises and become constant slightly in the simulated time.

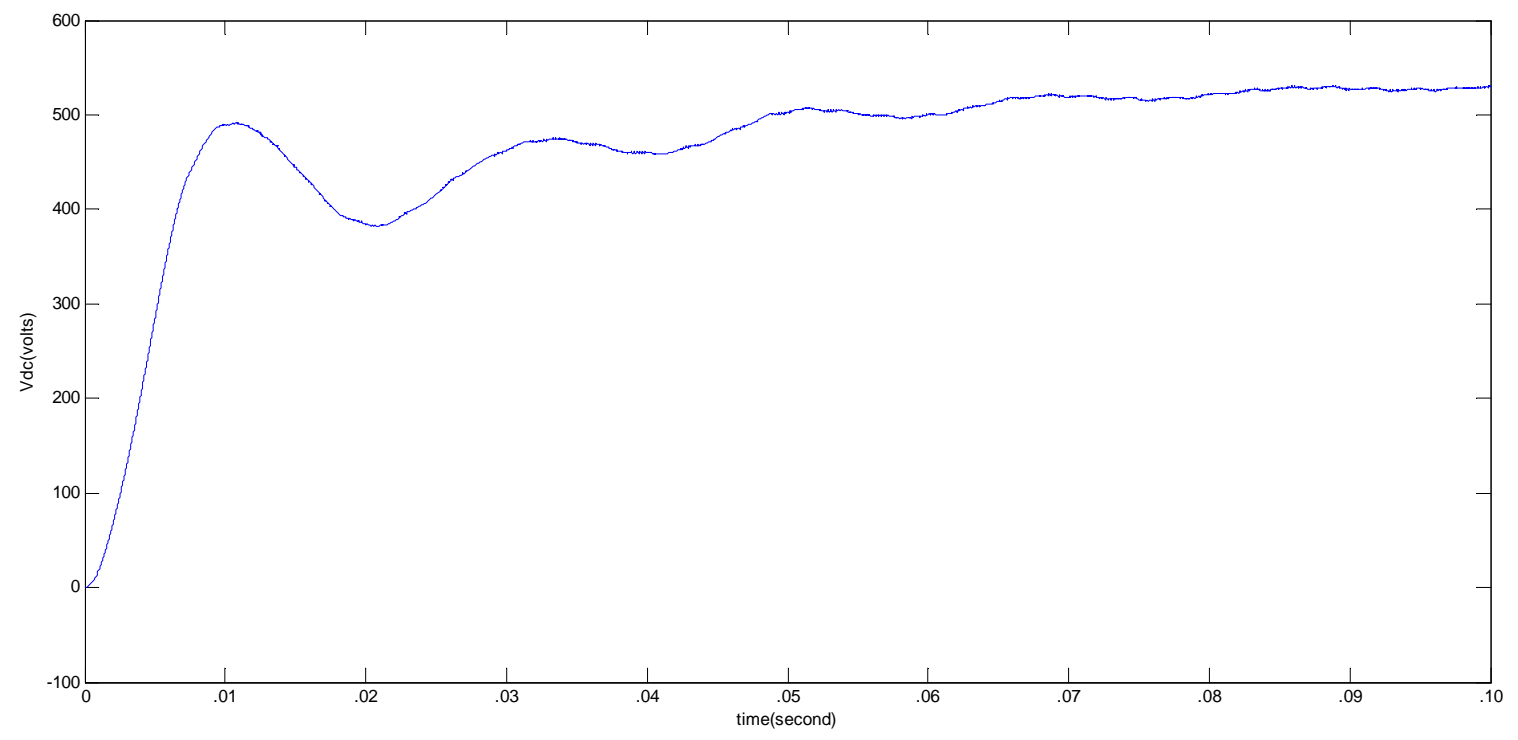

Figure 2. D.C voltage performance in the d.c link 


\subsection{Inverter voltage performance}

This d.c voltage is applied to the PWM inverter which converters the d.c in to a.c which is controlled the a.c voltage is zero in the initial at $\mathrm{t}=0$ because of the d.c supply is zero as the time goes on the variations are in the d.c according to the d.c variations the inverter output voltage is varying so for the it becomes slightly constant in the running time. Voltage is measured between the two phases of the inverter.

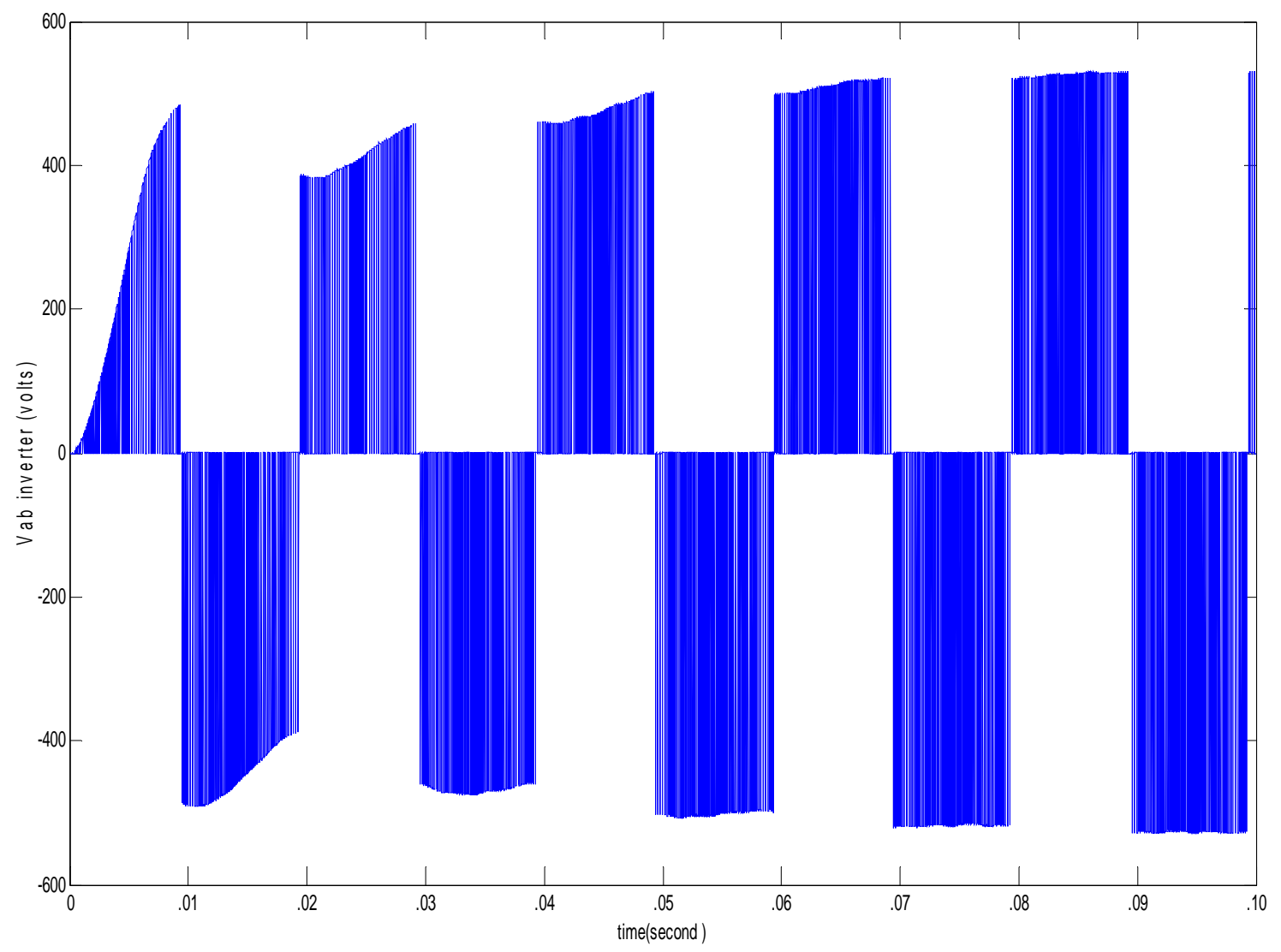

Figure 3. Inverter voltage performance between phase a and phase $b$

\subsection{Performance of the load voltage}

Output voltage of the inverter is first passed through the filter so the after filtration the supply is fed to the load. The running time is the .1 second so the performance in the form of the graph denotes that in the .1 second the load voltage consists of the five cycles. In the initial the load voltage is zero but as time goes the output voltage rises and varies sinusoidally voltage is regulated by the voltage regulator so for which is being constant in the five cycle so for we can say that the system is being stable in the .1 second. Voltage is being measured between the two phases. 


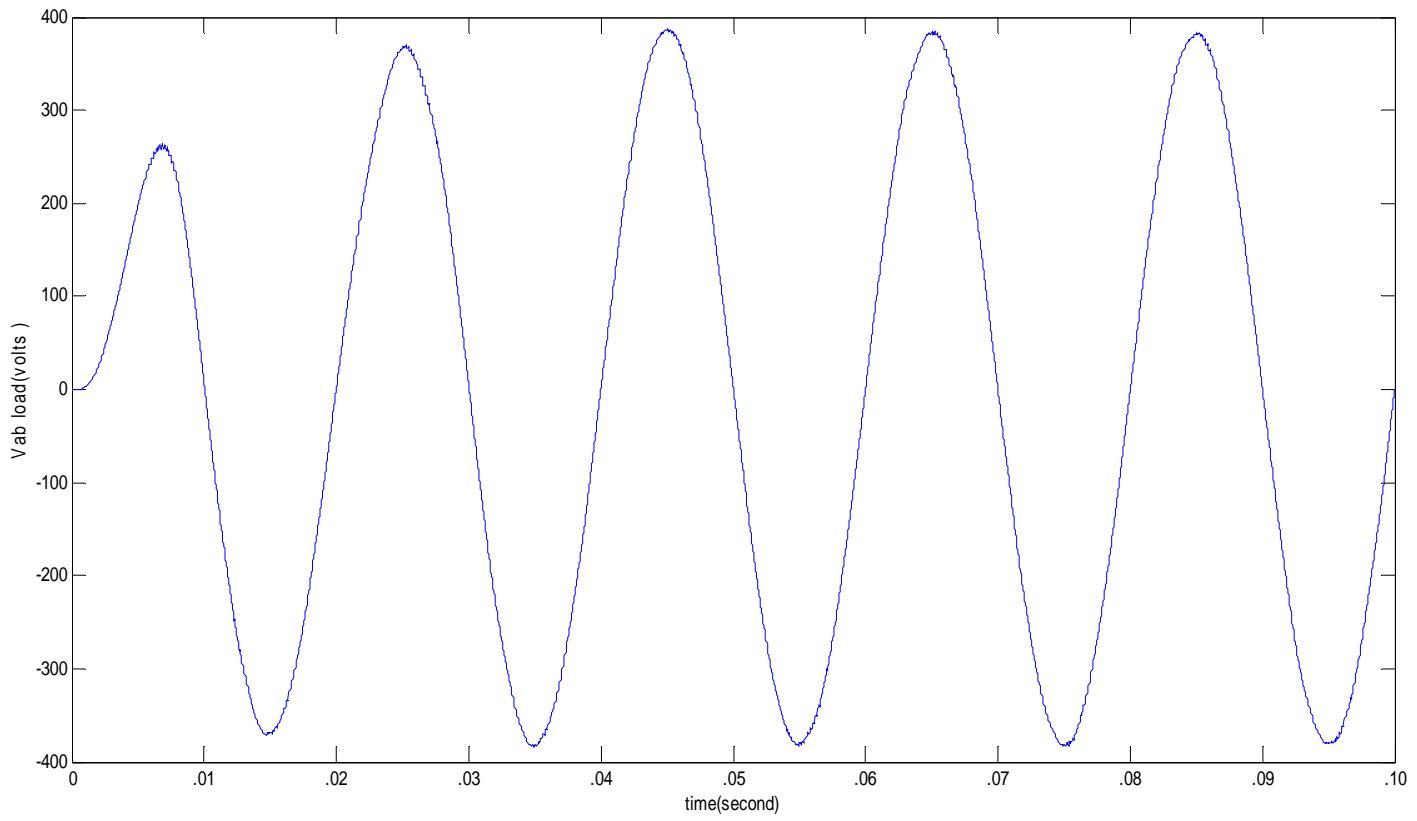

Figure 4. Load voltage performance between phase $a$ and $b$

\subsection{Performance of the Voltage regulator}

In the voltage regulator the modulation index is varying within the running time of the proposed model so for in the voltage regulator the comparison between the reference and require voltage occurs so for the variation of the modulation index is there at $\mathrm{t}=0$ it is zero which rises instantaneously to 1 after that is rises again as the time rises then as the time increase modulation index varies sinusoid ally and then it start decreasing at in the running time it at $\mathrm{t}=.1$ second modulation index become nearly constant

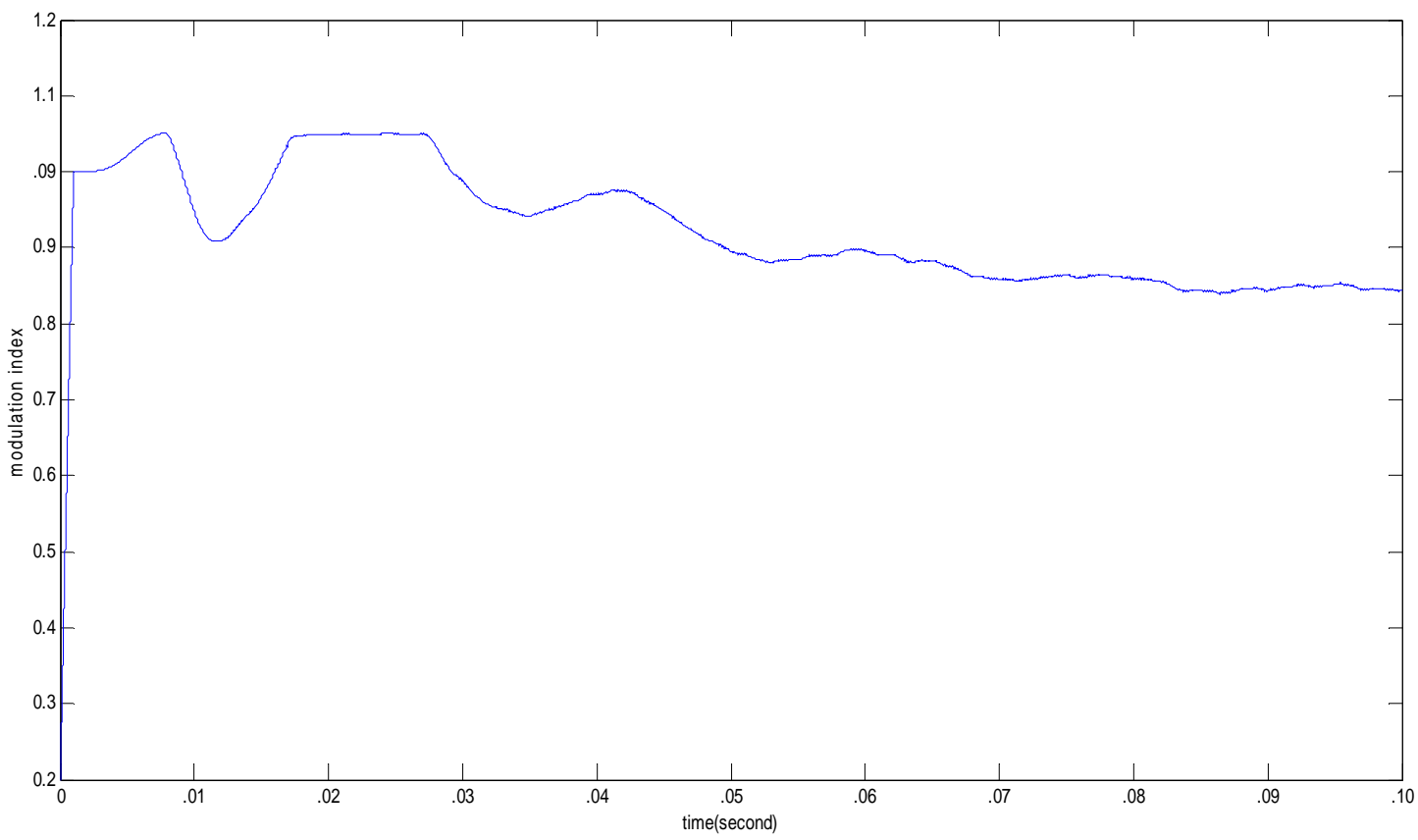

Figure 5. Modulation index performance 
So for we have used the proposed system for the fixed speed wind turbine it can be used in the variable speed wind turbine. We used the rectifier for the rectification of the a.c supply which is uncontrolled we can use controlled rectification. Controller used in the proposed system is PI we can use the Fuzzy logic controller so for the voltage regulation can also be improved.

\section{Conclusions}

In the paper presented an electrical energy system, consisting of diesel wind generator, since wind is absolutely free so no fuel cost. The production of the electrical energy the proposed scheme is economical. The proposed system is working at initial time $t=0$ to $t=0.10$ seconds, in each conditions the stability of the system is occurring within the $t=0.10$ seconds. At full load conditions the characteristics as shown reaches in steady state condition during at specified time .The proposed system has simulated at fixed speed and variable speed of wind turbine. It has developed the simulink based model of diesel wind generator with control rectifier in MATLAB. The performance analysis of developed voltage regulator have shown in figs.3fig.5 irrespective of d.c link voltage of converter, load voltage between two phases and performance of inverter at different modulation indices. It has observed the sinusoidal variation of output voltage with PWM. Mor reliable and stable operation of diesel wind generation with effective voltage regulation is observed.

\section{Nomenclature}

$i_{d s} \quad$ Direct axis stator current

$i_{q s} \quad$ Quadrature axis stator current

$i_{d r} \quad$ Direct axis Rotor current

$i_{q r} \quad$ Quadrature axis rotor current

[L] Inductance matrices of windings

[Y] Column matrices of flux linkage

[I] Column matrices of current

[V] Column matrices of voltages

[R] Diagonal resistance matrics

$\omega_{m} \quad$ Angular velocity of rotor

$\omega_{r} \quad$ Electrical angular velocity

$\omega \quad$ Rotational speed of rotating frame

$V_{d s} \quad$ Direct axis stator voltage

$V_{q s} \quad$ Quadrature axis stator voltage

$V_{d r} \quad$ Direct axis rotor voltage

$V_{q r} \quad$ Quadrature axis rotor voltage

$\varphi_{q s} \quad$ Stator flux component in $\mathrm{q}$ axis

$\varphi_{d s} \quad$ Stator flux component in $\mathrm{d}$ axis

$\varphi_{q r} \quad$ Rotor flux component in q axis

$\varphi_{d r} \quad$ Rotor flux component in $\mathrm{d}$ axis

$p_{z} \quad$ No. of pole pair

$T_{e} \quad$ Electromagnetic torque

$J \quad$ Inertia of load and rotor

$H \quad$ Combined load and rotor inertia constant

$F \quad$ Viscous friction coefficient of load and rotor

$T_{m} \quad$ Mechanical shaft torque

$\theta_{m} \quad$ Angular position Rotor

$P_{m} \quad$ Actual turbine power

$P_{\text {wind }} \quad$ Wind power

$E_{\text {wind }} \quad$ Kinetic energy of the wind

$t \quad$ Time

$m_{\text {wind }} \quad$ Mass of the wind

$\rho_{\text {air }} \quad$ Density of air

$A_{\text {blade }} \quad$ Area swept by air of blade

$V_{\text {wind }} \quad$ Velocity of wind

$C_{p} \quad$ Coefficient of performance for turbine function

$\lambda \quad$ Tip speed ratio 
$\beta \quad$ Pitch angle

$K_{p} \quad$ Proportional gain

$K_{i} \quad$ Integral gain

$s \quad$ Complex frequency

$K_{p t} \quad$ Total gain in diesel engine

$K_{1} \quad$ Constant gain

$K_{2} \quad$ Variable gain

$\tau_{1} \quad$ Dead time

$\tau_{2} \quad$ Actuator time constant

$N \quad$ Speed of the engine

$n \quad$ Number of cycles

PI Proportional Integration

$S_{t} \quad$ Strokes of the engine

$I G B T$ Insulated Gate Bipolar transistor

$P W M \quad$ Pulse width modulation

\section{References}

Andersen, 2007 Review of historical and modern utilization of wind power. Ris publication. pp.1-19.

Datta R., Ranganathan V. T., 2003. A method of tracking the peak power points for a variable speed wind energy conversion system. IEEE Transactions on Energy Conversion, Vol.18, No.1, pp.163-168.

Drouilhet S., 2001. Preparing an existing diesel power plant for a wind hybrid retrofit: lessons learned in thewales, alaska, winddiesel hybrid power project. Wind Power Conference, Washington D.C.,p.p1-10.

Mullane A., O'Malley M.,2005. The Inertial Response of Induction-Machine-Based Wind Turbine. IEEE Transactions on power systems, Vol.20, No.3, pp.1496-1503.

Pena R., C'ardenas R., Proboste J., Clare J., and Asher G., 2008.Wind-diesel generation using doubly fed induction machines. IEEE Transactions on Energy Conversion, Vol. 23, No.1, pp. 202-214.

Pinto A.C., Carvalho B.C., Oliveira J.C., Guimarães G.C., Moraes A.J., Salerno C.H., Vitório Z. S., 2006. Analysis of a WECS connected to utility grid with synchronous generator. IEEE PES Transmission and Distribution Conference and Exposition ,Latin America, Venezuela, p.p 1-6.

Srighakollap N.V.S., Sensarma P.S.,2008. Sensorless maximum power point tracking control in wind energy generation using permanent magnet synchronous generator. Proc. of IEEE-IECON'08, Orlando, USA.

Teri ENVIS Centre On Renewable Energy and Environment, 2005/2006.Wind energy information,pp.1-56.

Tianxiang W., Wanio H. and Iatneng C., 2010. New simulation technology in wind power system. University of Macau.

Vergauwe J., Martinez A., Ribas A., 2006. Optimization of a wind turbine using permanent magnet synchronous generator (PMSG). International Conference on Renewable and power Quality, Balearic Island.

Wang Q., Chang L., 2004. An intelligent maximum power traction algorithm for inverter-based variable speed wind turbine systems. IEEE Transactions on Power Electronics, Vol. 19, No.5, pp.1242-1249.

\section{Biographical notes}

Shashikant is pursuing M.Tech from Madan Mohan Malviya Engineering College Gorakhpur in the Department of the Electrical Engineering. His research interests include power system analysis,renewable energy system,non conventional energy resources and AI application in energy conversion systems.

Dr.S.K. Srivastava is an Associate Professor in the Department of the Electrical Engineering ,M.M.M. Engineering College Gorakhpur ,India .He has more than 23 years of experience in teaching and research .His current area of research includes FACTS and their controllers,Power Quality,Power system operation and control, non conventional energy resources and AI applications. He is fellow of IE(I) \& IETE India.

Received December 2010

Accepted March 2011

Final acceptance in revised form May 2011 